\title{
Erratum to: Different orders of one-sided scale elasticities in multi-output production
}

\author{
Petros Hadjicostas • Andreas C. Soteriou
}

Published online: 6 April 2010

(C) Springer Science+Business Media, LLC 2010

\section{Erratum to: J Prod Anal (2010) 33:147-167 \\ DOI 10.1007/s11123-009-0148-4}

The following list of corrections applies to the article, "Different orders of one-sided scale elasticities in multioutput production," by Petros Hadjicostas and Andreas C. Soteriou. The article appeared in the Journal of Productivity Analysis, Volume 33, Number 2, April 2010, pp. 147-167.

1. In p. 150 , column 1 , lines $10-11$, the sentence should read: "In Sect. 7 we give a second example that illustrates some of the ideas in our paper."

2. In p. 153, column 2, line 9 from the bottom (in the statement of Corollary 3.10), the end of the sentence should read: “ $\ldots$ such that $y_{0 i_{1}} \neq 0 \neq y_{0 i_{2}}$, then:".

3. In p. 155, column 1 , lines 19 and 15 from the bottom, the inequality $\frac{\partial \Phi}{\partial x_{t}}\left(X_{0}, Y_{0}\right)<0$ should become $\frac{\partial \Phi}{\partial x_{t}}\left(X_{0}, Y_{0}\right)$ $>0$.
4. In p. 165 , column 2, the mathematical expressions after line 13 should be corrected as follows:

$$
w_{k}^{*}=\left\{\begin{array}{ll}
w_{k} & \text { if } k \in K, \\
x_{k} & \text { if } k \in K^{c},
\end{array} \quad \text { for } k \in J(m),\right.
$$

and

$$
z_{i}^{*}=\left\{\begin{array}{ll}
z_{i} & \text { if } i \in M, \\
y_{i} & \text { if } i \in M^{c},
\end{array} \quad \text { for } i \in J(s) .\right.
$$

5. In p. 166 , column 1 , line 18 , the sentence should end as follows: “...with $\left(X^{\prime}\right)^{K^{c}}=X^{K^{c}}=W$."

6. In p. 167 , column 1 , lines 5 and 6 , the title of the reference should be corrected as follows: A note on "The use of categorical variables in Data Envelopment Analysis." (This is a note by W. A. Kamakura on another paper.)
The online version of the original article can be found under doi:10.1007/s11123-009-0148-4.

P. Hadjicostas $(\square)$

Department of Mathematics and Statistics, Texas Tech University, Box 41042, Lubbock, TX 79409-1042, USA

e-mail: petros.hadjicostas@ttu.edu

\section{A. C. Soteriou}

Department of Public and Business Administration,

School of Economics and Management, University of Cyprus,

P.O. Box 20537, Nicosia, CY 1678, Cyprus

e-mail: basotir@ucy.ac.cy 